\title{
PKD Regulates Membrane Fission to Generate TGN to Cell Surface Transport Carriers
}

\author{
Vivek Malhotra and Felix Campelo \\ Center for Genomic Regulation, Dr. Aiguader 88, Barcelona, Spain \\ Correspondence: vivek.malhotra@crg.es
}

\begin{abstract}
The serine/threonine protein kinase D (PKD) is recruited to the trans-Golgi network (TGN) by binding diacylglycerol (DAG) and the ARF1 GTPase. PKD, at the TGN, promotes the production of phosphatidylinositol-4 phosphate (PI4P) by activating the lipid kinase phophatidylinositol 4-kinase IIIß (PI4KIIIß). PI4P recruits proteins such as oxysterol-binding protein 1 (OSBP) and ceramide transport protein (CERT) that control sphingolipid and sterol levels at the TGN. CERT mediated transport of ceramide to the TGN, we suggest, is used for increasing the local production and concentration of DAG. Once the crucial concentration of DAG is achieved, OSBP and CERT dissociate from the TGN on phosphorylation by PKD and DAG is sequentially converted into phosphatidic acid (PA) and lyso-PA (LPA). Therefore, the net effect of the activated PKD at the TGN is the sequential production of the modified lipids DAG, PA, and LPA that are necessary for membrane fission to generate cell surface specific transport carriers.
\end{abstract}

\section{EXITING THE GOLGI: MULTIPLE ROUTES}

The Golgi complex is composed of cisternae

(flat membranes) that are stacked (in many cell types except, for example, Saccharomyces cerevisiae) and kept near the centrosomes in mammalian cells. These membranes receive and form transport carriers during protein secretion, but retain their overall identity. This level of organizational control is surprising considering that Golgi membranes have the capacity to reversibly breakdown completely into vesicles and tubules, for example, during mitosis. What are the components of membrane fission for biogenesis of transport carriers during protein secretion and how is this reaction regulated to prevent formation of empty carriers, to form carriers commensurate with cargo size, and to prevent complete vesiculation?
Unlike the endoplasmic reticulum (ER) that exports all of the secretory cargo to the Golgi (via the ER-Golgi intermediate compartment, ERGIC), there are multiple exit routes at the Golgi (Fig. 1), which include traffic to the endosomes by clathrin coated vesicles, to the ER by COPI coated vesicles and to the cell surface by transport carriers whose biochemical identity is unclear (Bard and Malhotra 2006). The exit routes to the cell surface can be further classified at least into an apical and basolateral pathway. The TGN also produces secretory storage granules. The overall number of the export pathways out of the Golgi varies depending on the cell type, for example, not all cells produce secretory storage granules from the Golgi apparatus. Do all transport carriers that form at the Golgi use the same fission components needed to separate the budding vesicle from the donor membrane?

Editors: Graham Warren and James Rothman

Additional Perspectives on The Golgi available at www.cshperspectives.org

Copyright (C) 2011 Cold Spring Harbor Laboratory Press; all rights reserved; doi: 10.1101/cshperspect.a005280

Cite this article as Cold Spring Harb Perspect Biol 2011;3:a005280 


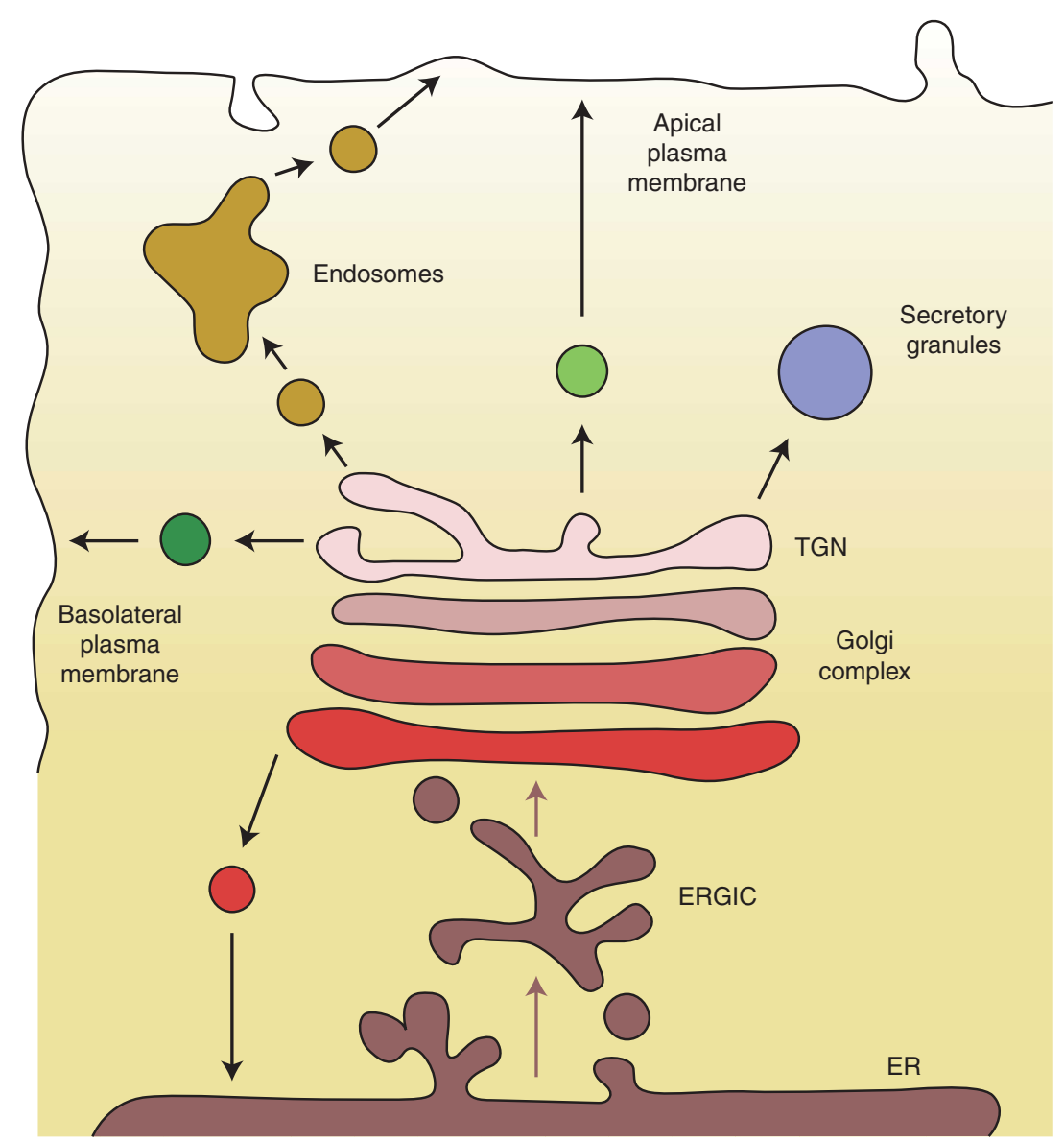

Figure 1. Exit routes for cargo at the Golgi. Although all proteins that exit the ER are transported by COPII vesicles to the ERGIC, there are numerous exit routes for cargo at the TGN. Traffic to the endosomes is mediated by clathrin coated vesicles; however, the molecular composition of transport carriers departing from the TGN to other cellular destinations is still unclear. Not all cells have the same exit routes and there are likely to be additional cell type dependent routes for cargo export from the Golgi. Do all transport vesicles that form at the TGN use the same fission components?

In sum, there are multiple exit routes from the Golgi, which are tightly guarded to prevent missorting and mistargeting of cargo. How are these export sites created, what are the components of the membrane fission process and how is this level of complexity regulated at the TGN?

\section{OVERACTIVATING MEMBRANE FISSION AT THE GOLGI: IDENTIFICATION OF PKD}

A sponge metabolite, Ilimaquinone (IQ), was found to convert Golgi cisternae into uniform sized vesicles in mammalian cells (Fig. 2). On removal of IQ, the Golgi assembled into a normal, fully functional, organelle (Takizawa et al. 1993). IQ treatment presumably overactivates the membrane fission machinery and thus provides a means to understand this biochemical reaction. Reconstitution of IQ mediated Golgi vesiculation revealed the involvement of trimeric $G$ protein subunits $B \gamma$ and a serine/threonine protein kinase termed PKD (Jamora et al. 1997; Jamora et al. 1999; Diaz Anel and Malhotra 2005). We tested whether these components were required for the fission of transport carriers at the Golgi. Chemical inactivation of PKD 


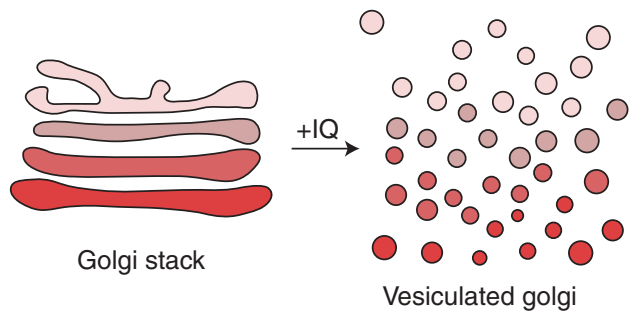

Figure 2. Ilimaquinone (IQ) cuts the entire Golgi apparatus to produce uniform size vesicles. The sponge natural metabolite Ilimaquinone vesiculates the Golgi apparatus by overactivating the membrane fission reaction. IQ-mediated Golgi vesiculation requires trimeric G protein and PKD. Surprisingly, however, PKD is required only for the fission of transport carriers containing the basolateral surface specific cargo at the TGN.

or expression of an inactive kinase inhibited trafficking of proteins from the Golgi to the basolateral cell surface. Cargo destined for the cell surface was contained in large tubules that remained attached to the TGN (Liljedahl et al. 2001). Overexpression of a constitutively activated $\mathrm{PKD}$, on the other hand, caused extensive vesiculation of the TGN (Bossard et al. 2007). PKD depletion by siRNA also shows cargo accumulation in tubular membranes at the TGN (Bossard et al. 2007). Without a functional PKD, the cargo-filled carriers grew into large tubules. These results led to the proposal that PKD was required for events leading to membrane fission specifically of carriers that transport cargo to the cell surface. A large number of other studies have reported the requirement of PKD in protein export from the Golgi (Irannejad and Wedegaertner 2010). A genetic screen in worms for acetylcholine secretion also identified PKD as a required component (Sieburth et al. 2005). Additionally, budding of large Herpes simplex virus type 1 capsids from the Golgi is also PKD dependent (Remillard-Labrosse et al. 2009). There are three isoforms of PKD in mammalian cells, called PKD1/PKC $\mu, \mathrm{PKD} 2$, and PKD3/ $\mathrm{PKC} v$ and all are involved in the formation of basolaterally directed transport carriers (Yeaman et al. 2004). All mammalian cells express at least two of the three isoforms of PKD, and PKD has orthologs in all eukaryotes except yeast
PKD Regulates Membrane Fission at the TGN

(Bossard et al. 2007). These proteins form both homo- and hetero-dimers at the TGN and inactivation or knockdown by siRNA of one partner inhibits Golgi to cell surface transport (Bossard et al. 2007).

Why does IQ treatment vesiculate the entire Golgi stack but PKD is required only for the events leading to the biogenesis, by fission, of Golgi to basolaterally targeted transport carriers? A simple possibility is that IQ activates cisternae specific pathways and we have thus far identified only components involved in the fission of the TGN. The more likely possibility is that IQ vesiculates only the TGN by a PKD dependent fission reaction. The preceding cisternae continue to follow their normal fate (cisternal maturation and/or vesicular transport) and without a functionally and structurally intact TGN as an acceptor, vesiculate completely. In other words, an intact TGN is necessary for the overall organization of other Golgi cisternae.

\section{RECRUITMENT OF PKD TO THE TGN: DAG AND ARF}

Of the two amino-terminal cysteine rich domains of PKD (Fig. 3A), the first or the Cla domain binds DAG at the TGN (Baron and Malhotra 2002). Proline 155 in the Cla domain was found to be essential for interaction with DAG in the TGN (Maeda et al. 2001). C1b, via proline 275 , has recently been shown to bind the GTPase ARF1 at the TGN (Pusapati et al. 2010) (Fig. 3B). Importantly, DAG is required for secretion in yeast and mammalian cells (Bankaitis 2002). Although the requirement for ARF in the formation of clathrin and COPI vesicles at the Golgi is well documented, a direct role for ARF in the formation of transport carriers that are directed to the cell surface, without transiting the endosomes, is not known. Inactivation of ARF1 by Brefeldin A (BFA) inhibits the recruitment of COPI (Orci et al. 1991). BFA treatment, however, does not dissociate PKD from the TGN (Maeda et al. 2001). This can be explained because along with ARF1, PKD binds DAG at the TGN and the latter interaction might be sufficient to retain PKD there. In 
V. Malhotra and F. Campelo

A
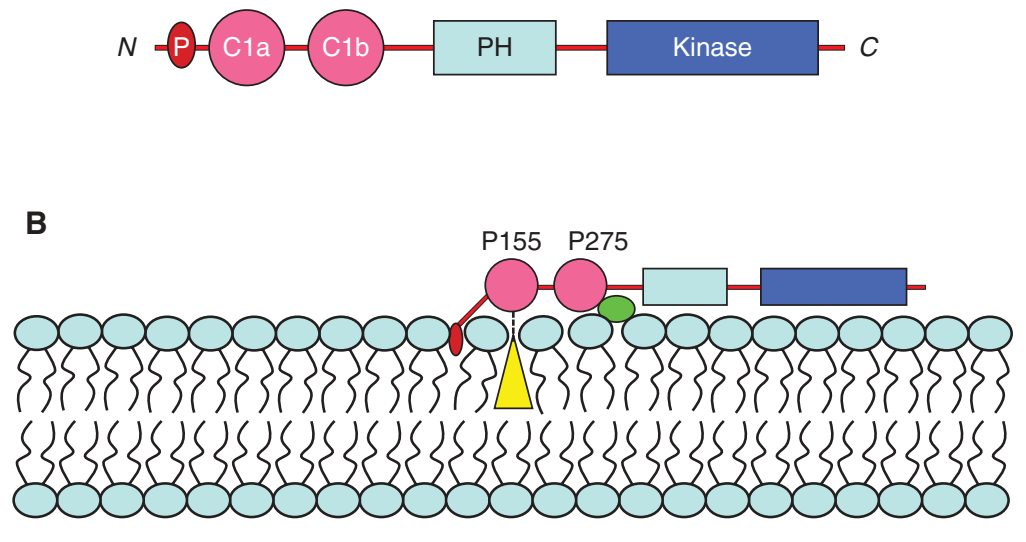

$\triangle \mathrm{DAG} \quad \bigcirc$ Arf1

Figure 3. Recruitment of PKD to the TGN. (A) The known domains of PKD. The PKD family in mammals comprises three members: PKD1, PKD2, and PKD3. All known members share a highly conserved amino-terminal regulatory domain, which is composed of two cysteine-rich domains ( $\mathrm{Cla}$ and $\mathrm{Clb}$ ) and an auto-inhibitory $\mathrm{PH}$ domain in addition to the catalytic kinase domain. PKD1 and PKD2 contain an amino-terminal hydrophobic stretch of amino acids (P), which we suggest penetrates the outer leaflet of the TGN. (B) The C1a domain of PKD binds DAG via proline 155. Proline 275 in the $\mathrm{C} 1 \mathrm{~b}$ domain of PKD is required for binding ARF1 at the TGN. These two domains in addition to the amino-terminal hydrophobic patch anchor PKD to the TGN. DAG bound to the C1a domain cannot flip across the bilayer and this is important, we suggest, to concentrate DAG in the outer leafter for events leading to membrane fission. ARF1 bound to the C1b domain of PKD cannot recruit COPI coats and we propose is required for the activation of PLD.

addition, PKD1 and PKD2 contain an aminoterminal stretch of hydrophobic amino acids (amino acids $3-55$ in PKD1, and 5-41 in PKD2), which we suggest are inserted into the outer leaflet of the TGN and would thus provide additional anchorage there (Fig. 3B). What then is the role of ARF in PKD dependent events at the TGN? A simple possibility is that ARF1 acts as a scaffold, in addition to DAG, to recruit PKD at the TGN. The other more attractive hypothesis is that PKD bound to activated ARF prevents the recruitment of COPI and clathrin coat components, and is used instead to activate phospholipase D (PLD) (Brown et al. 1993; Riebeling et al. 2009). Noteworthy is the finding that IQ mediated Golgi vesiculation is dependent on PLD (Sonoda et al. 2007). Because PKD is a downstream component of the IQ pathway, it is likely that PKD-bound ARF is used for the activation of PLD. PLD catalyzes the production of PA from phosphatidylcholine (PC) and we suggest that timely production of PA is required for events leading to membrane fission (Kooijman et al. 2003; Yang et al. 2008).

\section{ACTIVATION OF PKD AT THE TGN: KINASES, GPCRs, AND $\mathrm{Ca}^{2+}$}

IQ mediated Golgi vesiculation requires the trimeric $G$ protein subunits $G ß \gamma$, which were found to be necessary for PKD activation (Jamora et al. 1997; Jamora et al. 1999). Is Gßy localized at the Golgi and how does it activate PKD? It has been difficult to identify a Golgi specific trimeric $G$ protein mostly because of the inability to distinguish a resident protein from that en route to the cell surface. More recent studies suggest that M3-muscarinic-receptoractivated G protein $B \gamma$ (specifically, $\gamma 11$ ) subunits translocate from the plasma membrane to the Golgi in a signal dependent manner. Overstimulation of this signaling cascade caused 
Golgi fragmentation, which was inhibited by inactivation of PKD (Saini et al. 2010). This pathway was also shown to regulate insulin secretion (Saini et al. 2010). In another report, Gßy was shown to be at the Golgi and required for transport to the cell surface in a PKD dependent reaction (Irannejad and Wedegaertner 2010). Although these findings confirm the requirement of GBy in PKD dependent TGN to cell surface transport, the source of Gßy remains unresolved. Moreover, what is the function of $\mathrm{G} \alpha$ in this pathway?

The MAPK p388 negatively regulates PKD activity by phosphorylating serine 403 and 407 of mouse (serine 397 and 401 of human) PKD1. The $\mathrm{p} 38$ phosphorylated PKD was inactive in insulin secretion. Ablation of MAPK p38 in mouse was found to increase insulin secretion from pancreatic cells, which was PKD dependent. In other words, active MAPK p38 keeps PKD dependent insulin secretion in check (Sumara et al. 2009). There must therefore be a mechanism that alleviates the MAPK p38 dependent control of PKD activity. These findings implicate a signaling cascade that links

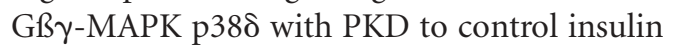
(or more generally Golgi to cell surface) secretion. The PH domain of PKD does not bind lipids and is suggested to be a negative regulator of PKD activity (Iglesias and Rozengurt 1998). Expression of the PH domain of PKD inhibited IQ- and Gßy-mediated Golgi fragmentation (Jamora et al. 1999). One likely possibility is that the PH domain of PKD binds Gßy and this alleviates the negative role of this $\mathrm{PH}$ domain on the kinase activity of PKD. Because MAPK $\mathrm{p} 38 \delta$ phosphorylates in the region within the $\mathrm{PH}$ and acidic domain of PKD, the phosphorylated form might not bind Gß $\gamma$ and would therefore be inactive in secretion (Fig. 4). In addition to the GBy and p38 dependent regulation, PKD is also activated by phosphorylation at the TGN by PKC $\eta$ (Diaz Anel and Malhotra 2005).

Newton and colleagues have recently reported that $\mathrm{Ca}^{2+}$ is required for the activation of PKD at the TGN (Kunkel and Newton 2010). The activation pathway that results in the increase in intracellular $\mathrm{Ca}^{2+}$ is also triggered by cell surface specific events. One possibility
PKD Regulates Membrane Fission at the TGN

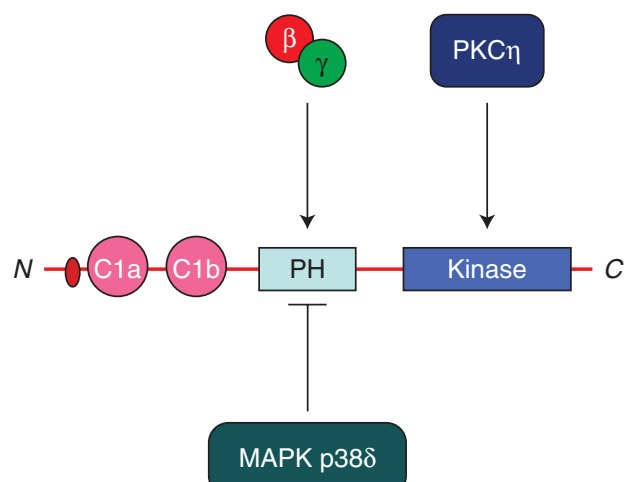

Figure 4. Activation of PKD. The PH domain of PKD is known to be a negative regulator of its kinase activity. Binding of Gß $\gamma$ would alleviate the negative effect of the PH on the kinase activity of PKD. The MAPK p38 phosphorylates in the $\mathrm{PH}$ domain to inactivate PKD. PKC $\eta$ is an activator of PKD. In addition, $\mathrm{Ca}^{2+}$ and DAG also control the activity and the duration of the kinase activity of PKD.

is that both $\mathrm{B} \gamma$ and $\mathrm{Ca}^{2+}$ are linked to the production of DAG at the TGN, which is required not only for the recruitment but also the activation of PKD (Oancea et al. 2003). This clearly shows the complex signaling at the TGN that regulates the location and activation (and the duration of the activation) of PKD at the TGN. What activates these upstream kinases to specifically control the activity of PKD in protein secretion is currently not known.

\section{PKD IS REQUIRED FOR THE LOCAL PRODUCTION OF MODIFIED LIPIDS AT THE TGN}

Cantley and colleagues found that PKD coprecipitated with two distinct lipid kinase activities: a PI4K and a PI4P5K (Nishikawa et al. 1998). PKD is now known to activate the enzyme PI4KIIIß, which generates PI4P from PI and both the enzyme and the phosphoinositide are required for Golgi to cell surface transport in yeast (Pik1p) (Walch-Solimena and Novick 1999) and mammalian cells (PI4KIIIß) (Hausser et al. 2005). (Fig. 5A) PKD is also known to regulate the activity of a type II PIP kinase which converts $\mathrm{PI} 5 P$ into $\mathrm{PI}(4,5) P_{2}$ 
V. Malhotra and F. Campelo
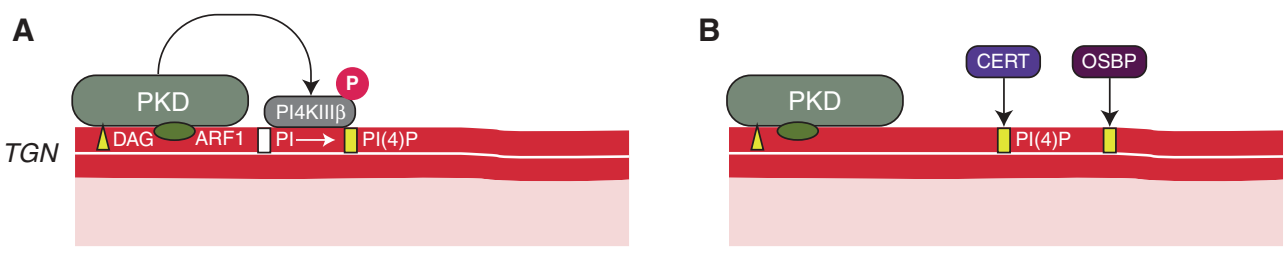

C

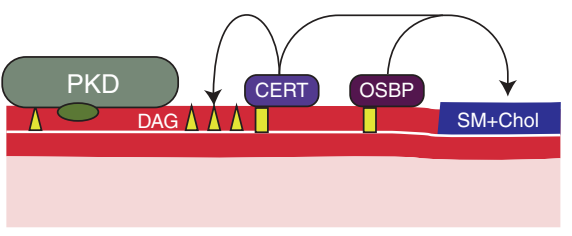

D

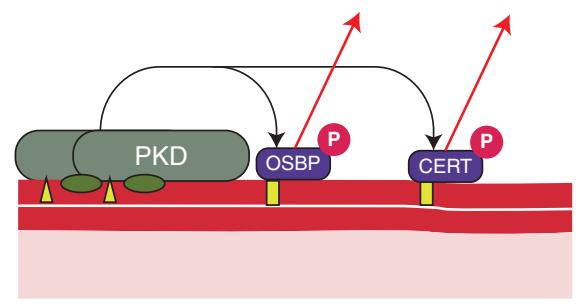

E

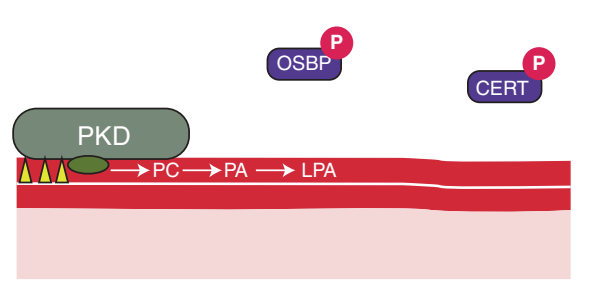

$\mathbf{F}$

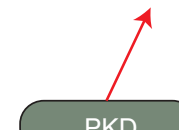

PKD

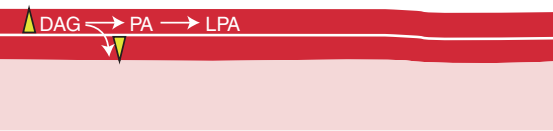

Figure 5. The effectors of PKD at the TGN. (A) PKD is recruited to the TGN by DAG and ARF1. Activated PKD phosphorylates to activate PI4KIIIß thus promoting the production of PI4P in the outer leaflet of the TGN. $(B)$ PI4P recruits a number of proteins to the TGN membrane, including OSBP and CERT. $(C)$ OSBP and CERT regulate the sphingomyelin and sterol levels in the TGN and this we suggest is required for separating the PI4P containing domain from the SM and sterol rich domain. CERT dependent ceramide transport to the TGN, we suggest is required to generate and concentrate DAG at the TGN. (D) This DAG in turn recruits more PKD to generate more DAG. PKD then phosphorylates OSBP and CERT to release them from the TGN. (E) ARF1 mediated activation of PLD1 generates PA from the PC pool, which eventually is converted to LPA by the action of PLA2. The accumulation of these different modified lipids leads to fission of TGN to cell surface transport carriers. $(F)$ DAG is consumed thus dissociating PKD from the membrane thus resetting the TGN to generate another round of transport carriers in a cargo-dependent manner.

(PIP2) (Hinchliffe and Irvine 2006). The PKD dependent phosphorylation of PIP kinase was mapped to threonine T376 and mutants in this residue are, enzymatically, less active (Hinchliffe and Irvine 2006). Although the role of PIP2 in traffic from the Golgi is not known, it provides evidence that PKD can, through activation of specific lipid kinases, generate both PI4P and PIP2. PI4P binds three other proteins at the TGN: OSBP, CERT and FAPP2 (Levine and Munro 1998; Nishikawa et al. 1998; Levine and Munro 2002; Godi et al. 2004) (Fig. 5B). OSBP is proposed to be a sterol sensor or transfer protein for cholesterol and 25-hydroxycholesterol; CERT is required for sphingomyelin
(SM) synthesis, and FAPP2 is required for the trafficking of glucosylceramide (Hanada et al. 2003; D’Angelo et al. 2007; Halter et al. 2007).

What then is the role of SM, sterols, glucosylceramide and PI4P at the TGN? CERT dependent transfer of ceramide from the ER to the TGN leads to the generation of sphingomyelin and DAG from phosphatidylcholine and ceramide at the TGN (Hanada et al. 2009). Sphingomyelin (SM) and cholesterol, we suggest, segregate from DAG, thus creating nonoverlapping domains at the TGN: one rich in $\mathrm{SM}$ and cholesterol and the other in DAG (Fig. 5C). DAG recruits more PKD (Fig. 5D). This has two effects on the lipid composition of the 
outer leaflet of TGN. We propose that binding of PKD to DAG prevents it from flipping across the membrane. This concentrates DAG in the outer leaflet. PKD, which binds to ARF1 via its second cysteine rich domain promotes ARF dependent activation of phospholipase D (PLD) to produce PA from phosphatidylcholine (PC). PA has a high affinity for divalent cations $\left(\mathrm{Ca}^{2+}, \mathrm{Mg}^{++}\right)$and is capable of assembling into microdomains of higher lipid packing order (Kooijman et al. 2003; Faraudo and Travesset 2007; Kooijman and Burger 2009). A phospholipase A2 (PLA2) converts PA into lyso-PA (LPA) (San Pietro et al. 2009), which has a large positive spontaneous curvature (Kooijman et al. 2005; Zimmerberg and Kozlov 2006) (Fig. 5E). Additionally, both PKD1 and PKD2 contain a small stretch of hydrophobic amino acids at the Amino terminus, which insert into the outer lipid leaflet and it has been suggested that shallow insertion of small hydrophobic groups can generate membrane curvature (McMahon and Gallop 2005; Zimmerberg and Kozlov 2006; Campelo et al. 2008). The net effect of pulling this PKD containing-LPA enriched domain would thus create a bud. DAG would be pulled at the neck of the growing bud and stabilize the neck geometry preventing fission (Shemesh et al. 2003). Rapid conversion of DAG into the fissionpromoting lipids PA and/or LPA would ultimately cause the neck to break from the TGN membrane thus liberating a cargo filled carrier (Kozlovsky and Kozlov 2003) (Fig. 5F). The timing of the conversion of DAG into PA and/ or LPA could thus be used to regulate the dimensions of the transport carrier. The carrier formation is terminated by PKD dependent phosphorylation of OSBP and CERT and their dissociation from the TGN as reported (Fugmann et al. 2007; Nhek et al. 2010). Although the DAG-PKD domain is used for the generation of basolaterally targeted transport carriers, the SM- and cholesterol-enriched domain would be used for the generation of carriers containing the apically targeted cargo (Nhek et al. 2010).

In other words, the recruitment of PKD to the TGN initiates the events that create and
PKD Regulates Membrane Fission at the TGN

regulate the growth of export domains at the TGN. These export domains at the TGN would thus be created and consumed in a cargo dependent manner and would be different from the stable ER sites for export of secretory cargo. PI4P, DAG, and PA play key roles in the events by which the PKD containing export domain is pinched from the TGN, thus generating a transport carrier. The timing of the production of these modified lipids is very important and new components, in addition to those known thus far, are likely to be involved in membrane fission. The obvious challenge is to reconstitute budding of cargo-filled transport carriers by the addition of pure proteins that produce the lipids described above. Quantitation of lipids generated and imaging of Golgi membranes during such incubations will be the real test of their proposed roles.

\section{REFERENCES}

Bankaitis VA. 2002. Cell biology. Slick recruitment to the Golgi. Science 295: 290-291.

Bard F, Malhotra V. 2006. The formation of TGN-toplasma-membrane transport carriers. Annu Rev Cell Dev Biol 22: 439-455.

Baron CL, Malhotra V. 2002. Role of diacylglycerol in PKD recruitment to the TGN and protein transport to the plasma membrane. Science 295: 325-328.

Bossard C, Bresson D, Polishchuk RS, Malhotra V. 2007. Dimeric PKD regulates membrane fission to form transport carriers at the TGN. J Cell Biol 179: 1123-1131.

Brown HA, Gutowski S, Moomaw CR, Slaughter C, Sternweis PC. 1993. ADP-ribosylation factor, a small GTPdependent regulatory protein, stimulates phospholipase D activity. Cell 75: 1137-1144.

Campelo F, McMahon HT, Kozlov MM. 2008. The hydrophobic insertion mechanism of membrane curvature generation by proteins. Biophys J 95: 2325-2339.

D’Angelo G, Polishchuk E, Di Tullio G, Santoro M, Di Campli A, Godi A, West G, Bielawski J, Chuang CC, van der Spoel AC, et al. 2007. Glycosphingolipid synthesis requires FAPP2 transfer of glucosylceramide. Nature 449: 62-67.

Diaz Anel AM, Malhotra V. 2005. PKCeta is required for $\beta 1 \gamma 2 / \beta 3 \gamma 2$ - and PKD-mediated transport to the cell surface and the organization of the Golgi apparatus. $J$ Cell Biol 169: 83-91.

Faraudo J, Travesset A. 2007. Phosphatidic acid domains in membranes: effect of divalent counterions. Biophys J 92: 2806-2818.

Fugmann T, Hausser A, Schoffler P, Schmid S, Pfizenmaier K, Olayioye MA. 2007. Regulation of secretory transport 
V. Malhotra and F. Campelo

by protein kinase $\mathrm{D}$-mediated phosphorylation of the ceramide transfer protein. J Cell Biol 178: 15-22.

Godi A, Di Campli A, Konstantakopoulos A, Di Tullio G, Alessi DR, Kular GS, Daniele T, Marra P, Lucocq JM, De Matteis MA. 2004. FAPPs control Golgi-to-cellsurface membrane traffic by binding to ARF and PtdIns(4)P. Nat Cell Biol 6: 393-404.

Halter D, Neumann S, van Dijk SM, Wolthoorn J, de Maziere AM, Vieira OV, Mattjus P, Klumperman J, van Meer G, Sprong H. 2007. Pre- and post-Golgi translocation of glucosylceramide in glycosphingolipid synthesis. $J$ Cell Biol 179: 101-115.

Hanada K, Kumagai K, Tomishige N, Yamaji T. 2009. CERTmediated trafficking of ceramide. Biochim Biophys Acta 1791: 684-691.

Hanada K, Kumagai K, Yasuda S, Miura Y, Kawano M, Fukasawa M, Nishijima M. 2003. Molecular machinery for non-vesicular trafficking of ceramide. Nature 426: 803-809.

Hausser A, Storz P, Martens S, Link G, Toker A, Pfizenmaier K. 2005. Protein kinase D regulates vesicular transport by phosphorylating and activating phosphatidylinositol-4 kinase III $\beta$ at the Golgi complex. Nat Cell Biol 7: $880-886$.

Hinchliffe KA, Irvine RF. 2006. Regulation of type II PIP kinase by PKD phosphorylation. Cell Signal 18: 19061913.

Iglesias T, Rozengurt E. 1998. Protein kinase D activation by mutations within its pleckstrin homology domain. J Biol Chem 273: 410-416.

Irannejad R, Wedegaertner PB. 2010. Regulation of constitutive cargo transport from the trans-golgi network to plasma membrane by golgi-localized $\mathrm{G}$ protein betagamma subunits. J Biol Chem 285: 32394-32404.

Jamora C, Takizawa PA, Zaarour RF, Denesvre C, Faulkner DJ, Malhotra V. 1997. Regulation of Golgi structure through heterotrimeric $\mathrm{G}$ proteins. Cell 91: 617-626.

Jamora C, Yamanouye N, Van Lint J, Laudenslager J, Vandenheede JR, Faulkner DJ, Malhotra V. 1999. $\mathrm{G} \beta \gamma$-mediated regulation of Golgi organization is through the direct activation of protein kinase D. Cell 98: $59-68$.

Kooijman EE, Burger KN. 2009. Biophysics and function of phosphatidic acid: a molecular perspective. Biochim Biophys Acta 1791: 881-888.

Kooijman EE, Chupin V, de Kruijff B, Burger KN. 2003. Modulation of membrane curvature by phosphatidic acid and lysophosphatidic acid. Traffic 4: 162-174.

Kooijman EE, Chupin V, Fuller NL, Kozlov MM, de Kruijff B, Burger KN, Rand PR. 2005. Spontaneous curvature of phosphatidic acid and lysophosphatidic acid. Biochemistry 44: 2097-2102.

Kozlovsky Y, Kozlov MM. 2003. Membrane fission: model for intermediate structures. Biophys J 85: 85-96.

Kunkel MT, Newton AC. 2010. Calcium transduces plasma membrane receptor signals to produce diacylglycerol at Golgi membranes. J Biol Chem 285: 22748-22752.

Levine TP, Munro S. 1998. The pleckstrin homology domain of oxysterol-binding protein recognises a determinant specific to Golgi membranes. Curr Biol 8: 729-739.
Levine TP, Munro S. 2002. Targeting of Golgi-specific pleckstrin homology domains involves both PtdIns 4-kinase-dependent and -independent components. Curr Biol 12: 695-704.

Liljedahl M, Maeda Y, Colanzi A, Ayala I, Van Lint J, Malhotra V. 2001. Protein kinase D regulates the fission of cell surface destined transport carriers from the trans-Golgi network. Cell 104: 409-420.

Maeda Y, Beznoussenko GV, Van Lint J, Mironov AA, Malhotra V. 2001. Recruitment of protein kinase D to the trans-Golgi network via the first cysteine-rich domain. Embo J 20: 5982-5990.

McMahon HT, Gallop JL. 2005. Membrane curvature and mechanisms of dynamic cell membrane remodelling. Nature 438: 590-596.

Nhek S, Ngo M, Yang X, Ng MM, Field SJ, Asara JM, Ridgway ND, Toker A. 2010. Regulation of oxysterolbinding protein golgi localization through protein kinase D-mediated phosphorylation. Mol Biol Cell 21: 2327-2337.

Nishikawa K, Toker A, Wong K, Marignani PA, Johannes FJ, Cantley LC. 1998. Association of protein kinase Cmu with type II phosphatidylinositol 4-kinase and type I phosphatidylinositol-4-phosphate 5-kinase. J Biol Chem 273: 23126-23133.

Oancea E, Bezzerides VJ, Greka A, Clapham DE. 2003. Mechanism of persistent protein kinase D1 translocation and activation. Dev Cell 4: 561-574.

Orci L, Tagaya M, Amherdt M, Perrelet A, Donaldson JG, Lippincott-Schwartz J, Klausner RD, Rothman JE. 1991. Brefeldin A, a drug that blocks secretion, prevents the assembly of non-clathrin-coated buds on Golgi cisternae. Cell 64: 1183-1195.

Pusapati GV, Krndija D, Armacki M, von Wichert G, von Blume J, Malhotra V, Adler G, Seufferlein T. 2010. Role of the second cysteine-rich domain and Pro275 in protein kinase D2 interaction with ADP-ribosylation factor 1, trans-Golgi network recruitment, and protein transport. Mol Biol Cell 21: 1011-1022.

Remillard-Labrosse G, Mihai C, Duron J, Guay G, Lippe R. 2009. Protein kinase D-dependent trafficking of the large Herpes simplex virus type 1 capsids from the TGN to plasma membrane. Traffic 10: 1074-1083.

Riebeling C, Morris AJ, Shields D. 2009. Phospholipase D in the Golgi apparatus. Biochim Biophys Acta 1791: $876-880$.

Saini DK, Karunarathne WK, Angaswamy N, Saini D, Cho JH, Kalyanaraman V, Gautam N. 2010. Regulation of Golgi structure and secretion by receptor-induced $\mathrm{G}$ protein $\beta \gamma$ complex translocation. Proc Natl Acad Sci 107: 11417-11422.

San Pietro E, Capestrano M, Polishchuk EV, DiPentima A, Trucco A, Zizza P, Mariggio S, Pulvirenti T, Sallese M, Tete S, et al. 2009. Group IV phospholipase A(2) $\alpha$ controls the formation of inter-cisternal continuities involved in intra-Golgi transport. PLoS Biol 7: e1000194.

Shemesh T, Luini A, Malhotra V, Burger KN, Kozlov MM. 2003. Prefission constriction of Golgi tubular carriers driven by local lipid metabolism: A theoretical model. Biophys J 85: 3813-3827. 
Sieburth D, Ch'ng Q, Dybbs M, Tavazoie M, Kennedy S, Wang D, Dupuy D, Rual JF, Hill DE, Vidal M, et al. 2005. Systematic analysis of genes required for synapse structure and function. Nature 436: 510-517.

Sonoda H, Okada T, Jahangeer S, Nakamura S. 2007. Requirement of phospholipase D for ilimaquinoneinduced Golgi membrane fragmentation. J Biol Chem 282: 34085-34092.

Sumara G, Formentini I, Collins S, Sumara I, Windak R, Bodenmiller B, Ramracheya R, Caille D, Jiang H, Platt KA, et al. 2009. Regulation of PKD by the MAPK p38 in insulin secretion and glucose homeostasis. Cell 136: 235-248.

Takizawa PA, Yucel JK, Veit B, Faulkner DJ, Deerinck T, Soto G, Ellisman M, Malhotra V. 1993. Complete vesiculation of Golgi membranes and inhibition of protein transport
PKD Regulates Membrane Fission at the TGN

by a novel sea sponge metabolite, ilimaquinone. Cell 73: 1079-1090.

Walch-Solimena C, Novick P. 1999. The yeast phosphatidylinositol-4-OH kinase pik1 regulates secretion at the Golgi. Nat Cell Biol 1: 523-525.Yang JS, Gad H, Lee SY, Mironov A, Zhang L, Beznoussenko GV, Valente C, Turacchio G, Bonsra AN, Du G, et al. 2008. A role for phosphatidic acid in COPI vesicle fission yields insights into Golgi maintenance. Nat Cell Biol 10: 1146-1153.

Yeaman C, Ayala MI, Wright JR, Bard F, Bossard C, Ang A, Maeda Y, Seufferlein T, Mellman I, Nelson WJ, et al. 2004. Protein kinase $\mathrm{D}$ regulates basolateral membrane protein exit from trans-Golgi network. Nat Cell Biol 6: $106-112$.

Zimmerberg J, Kozlov MM. 2006. How proteins produce cellular membrane curvature. Nat Rev Mol Cell Biol 7: 9-19. 


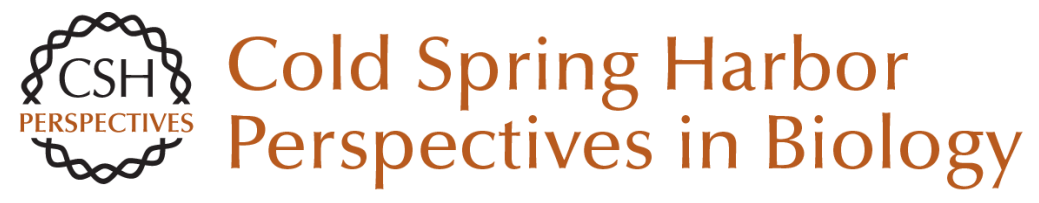

\title{
PKD Regulates Membrane Fission to Generate TGN to Cell Surface Transport Carriers
}

\author{
Vivek Malhotra and Felix Campelo
}

Cold Spring Harb Perspect Biol 2011; doi: 10.1101/cshperspect.a005280 originally published online January 19, 2011

\section{Subject Collection The Golgi}

\section{Structure of Golgi Transport Proteins}

Daniel Kümmel and Karin M. Reinisch

\section{Golgi Biogenesis}

Yanzhuang Wang and Joachim Seemann

Golgi Glycosylation and Human Inherited

Diseases

Hudson H. Freeze and Bobby G. Ng

Models for Golgi Traffic: A Critical Assessment Benjamin S. Glick and Alberto Luini

Architecture of the Mammalian Golgi Judith Klumperman

Evolution and Diversity of the Golgi Mary J. Klute, Paul Melançon and Joel B. Dacks

Evolutionary Forces Shaping the Golgi Glycosylation Machinery: Why Cell Surface

Glycans Are Universal to Living Cells Ajit Varki

Golgi Positioning

Smita Yadav and Adam D. Linstedt
Golgi and Related Vesicle Proteomics: Simplify to Identify Joan Gannon, John J.M. Bergeron and Tommy Nilsson

Organization of SNAREs within the Golgi Stack Jörg Malsam and Thomas H. Söllner

Golgi during Development Weimin Zhong

Entry and Exit Mechanisms at the cis-Face of the Golgi Complex Andrés Lorente-Rodríguez and Charles Barlowe COPI Budding within the Golgi Stack Vincent Popoff, Frank Adolf, Britta Brügger, et al.

Mechanisms of Protein Retention in the Golgi David K. Banfield

The Golgin Coiled-Coil Proteins of the Golgi

Apparatus Sean Munro

Signaling at the Golgi Peter Mayinger

For additional articles in this collection, see http://cshperspectives.cshlp.org/cgi/collection/

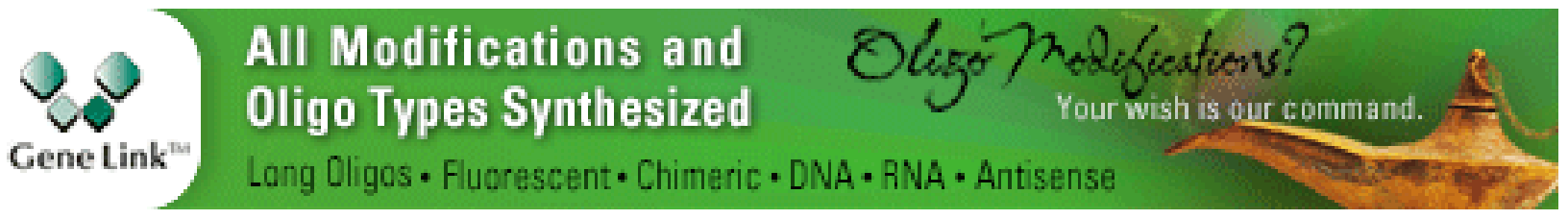

